Revista Iberoamericana. Vol. LXII, Núms. 176-177, Julio-Diciembre 1996; 799-820

\title{
ESTADOS DE DESEO: HOMOSEXUALIDAD Y NACIONALIDAD (JUAN GOYTISOLO Y REINALDO ARENAS A VUELAPLUMA)
}

\author{
POR \\ BRAD EpPS \\ Harvard University
}

Para Juan y Rubén

"Plumas, sí, deliciosas plumas de azufre, río de plumas arrastrando cabezas de mármol, plumas en la cabeza, sombrero de plumas, colibríes y frambuesas" (91). ${ }^{1} \mathrm{Y}$ también: "una montaña de plumas: plumas en la cabeza, plumas en las alas de mis brazos, plumas en mi lindo trasero" (44). Dejando flotar las plumas que acabo de citar de Severo Sarduy y de Carlos Varo, quisiera lanzar al aire otras plumas. Quisiera considerar, a vuelapluma, el correr de la pluma de Juan Goytisolo y Reinaldo Arenas, algunos giros especiales en las carreras y corridas, literarias y no, de dos escritores cuya obra lleva la marca de la homosexualidad. Semejante marca no es sencilla, pero suele recibir poca atención por parte de la crítica: como si con sólo mencionar la homosexualidad ya no hubiera más que decir; como si la homosexualidad fuera siempre, y en todas partes, lo mismo; o, más aun, como si la homosexualidad estuviera de más en un estudio sobre la literatura o la cultura, como si resultara excesiva o anodina, insignificante o "impropia," demasiado personal o epifenoménica, hasta en un estudio sobre aquellos textos y escritores en los que figura de forma central.

Las plumas de las plumas - metáforicas, ya se sabe- de Goytisolo y Arenas permanecen, o al menos deberían permanecer, para algunos, en un plano estrictamente metáforico, más allá (o más acá) de toda preocupación social, ética, o política. Oscar Montero ha declarado que "una estrategia dominante de la supresión consiste en excluir la homosexualidad de todo texto escrito que no sea médico o legal, es decir en excluirla de la literatura" (101). Montero se refiere a la obra de Julián del Casal y a la Cuba del siglo pasado, pero su observación, debidamente recontextualizada, es tristemente válida para gran parte de la actualidad crítica: la homosexualidad bien puede enseñar sus plumas en la literatura,

\footnotetext{
${ }^{1}$ Una primera versión de este trabajo fue presentada, en inglés, en una conferencia especial sobre cuestiones de nacionalidad y subjetividad celebrada en la Rutgers University el 27 y el 28 de marzo de 1996; una segunda versión, esta vez en castellano, fue presentada en el Seminario Federico de Onís de la Universidad de Puerto Rico, Río Piedras, el 11 de abril de 1996. Quisiera darles las gracias a Juan Gelpí, Rubén RíosÁvila, Carlos Varo, Francine Masiello, Mary Gossy y Nicholas Shumway por sus comentarios. Todas las traducciones de textos citados en la bibliografia en inglés (incluso los de Freud) son mías.
} 
pero la crítica no tiene por qué, tal vez no debe, prestarle tanta atención. Sacar estas plumas a la luz y prestarles atención como indicios de algo homosexual, literario, y político a la vez es, no obstante, lo que pretendo hacer aquí. Centrándome en cuestiones de enunciación y, sobre todo, de interpelación, examinaré primero algunas de las tensiones entre homosexualidad y nacionalidad, tensiones inscritas en la literatura pero no limitadas a ella, para pasar luego a algunos textos, ficticios y autobiográficos, de Reinaldo Arenas y Juan Goytisolo. El presente artículo es, por lo tanto, menos un paseo por la obra de dos "maestros" de la escritura que un sobrevuelo de ciertos problemas de plumas dentro del contexto del hispanismo, ${ }^{2}$ problemas que implican una variedad de papeles y posturas personales: sobre todo, pero no tan sólo, el yo, el tú y el nosotros/nosotras.

LUGARES, TIEMPOS, Y TRAYECTORIAS DEL DISCURSO NACIONAL-SEXUAL

¿Qué país inventado en la memoria se vuelve macharrán con su desprecio hartísimo de tanta vanagloria?

Manuel Ramos Otero, de Invitación al polvo

Sigmund Freud, en su discurso sobre la "Femenidad", se dirige al público de una forma harto reveladora. Confesando que está "luchando con una dificultad interior", a saber, "los límites de su licencia para hablar", Freud asevera que "a lo largo de la historia la gente se ha devanado los sesos con el acertijo de la naturaleza de la feminidad". La "gente" así

\footnotetext{
${ }^{2}$ Semejante contexto, como señalan Emilie Bergmann y Paul Julian Smith, es inevitablemente fragmentado y fragmentario, y guarda una relación "claramente problemática" (2) con la teoría "queer" tal y como se practica en los Estados Unidos, Gran Bretaña y Francia. La relación con teorías y prácticas, dentro y fuera de estos países, que rehúsan o soslayan la designación "queer" también es "problemática". Parte del problema, tal vez gran parte del problema, es de orden lingüístico, a saber, cómo designar, señalar y llamar, cómo significar. Bergmann y Smith indican algo parecido al afirmar que "si los escritores y artistas de [su] colección tienen un hogar o una nación no es un territorio geográfico sino más bien las múltiples y variadas formas de la lengua española" (1). La noción de la lengua como nación es consoladora y, por esto mismo, "problématica" también. Entre muchas otras cosas, sugiere, aunque sea sotto voce, que toda traducción es una traición, que pasar de una lengua a otra - y no se trata aquí, o al menos no sólo, de un beso bilingüe - es pasarse o intentar pasarse de esta lengua, esta nación. Pretender, por ejemplo, que el término "queer" se traduzca al español (como "maricón" o "maricona" o lo que sea) o que sea capaz de designar "las múltiples y variadas formas" del español corre el riesgo de pasar por alto la dificultad, si no la imposibilidad, de encontrar equivalencias "no problemáticas" y verdaderamente "internacionales". Bergmann y Smith parecen saber que reconocer y examinar "las fronteras nacionales y lingüísticas implica una labor lenta y paciente de traducción" (9). Esta labor bien podría comenzar con un reconocimiento de que no todo se deja traducir, que tal vez siempre habrá este tipo de dificultades que, por sutiles que sean, delatan un territorio que no es, así en abstracto, la lengua española. Dicha lengua, como quizás toda lengua, se trabaja y se traba de acuerdo con nociones nacionales e internacionales, material istas e imaginativas, que marcan hasta el yo más declaradamente individual. En lo que sigue, movilizaré este yo, el mío, en una lengua que no es la mía para intentar iluminar - y tal vez oscurecer- no sólo el "juego" de posesiones, propiedades y personalidades nacionales y sexuales, sino también sus complicidades y colectividades, sus relaciones con ellos, los otros, los demás, y, cómo no, "nosotros" mismos.
} 
ocupada no es, sin embargo, toda la gente, ya que Freud hace una distinción importante que le implica a él tanto como a quienes le escuchan: "ustedes no se habrán librado de preocuparse por este problema - me refiero a aquellos de ustedes que son hombres- en cuanto a las mujeres, esto no se aplicará —ustedes mismas son el problema". Me siento tentado, tal vez perversamente, a torcer en otra dirección el discurso de Freud. Al proponerme escribir sobre la homosexualidad, podría decir, a caballo entre la ironía y la seriedad, que mientras que los que entre ustedes son heterosexuales tal vez no se hayan librado de preocuparse por este problema, los que entre ustedes son homosexuales constituyen, ustedes mismos, el problema. Estas distinciones dan, después de todo, la medida de una dificultad de la que yo tampoco me puedo escapar: la dificultad de dirigirse a otro, la dificultad de la interpelación, y del contexto, o lugar, de la enunciación. Sería reconfortante, supongo, que me desmarcara de Freud, que lo trajera a colación sólo para descartarlo, pero no lo evoco por nada tan fácil. Más bien, lo cito, no tanto por lo que dice como por dónde, cómo, y a quiénes lo dice. Su discurso sobre la "Feminidad" podría haber formado parte de unaserie de discursos pronunciados en Viena ante un público mayoritariamente académico, pero por razones de edad y de salud Freud nunca llegó a darlo. Sin embargo, Freud afirma que puede situarse, mediante "el artificio de la imaginación"(5), en la sala de discursos, que puede dar el discurso sin realmente darlo. "Habla", pero decirlo así, por escrito, digiriéndose a sus lectores, a sus "auditores imaginarios".

Ahora bien, el hecho de hablar, en persona y en público, no puede reducirse al hecho de escribir, incluso si se recurre al artificio de la imaginación (imaginando que los lectores oyen, que escuchan), como tampoco puede equipararse la interpelación aparentemente directa (yo te hablo) con la interpelación claramente mediatizada (yo [te] escribo). No quiero entrar en la maraña de las relaciones entre el habla y la escritura, pero sí quiero recalcar que la interpelación (como evidentemente la enunciación) funciona también por escrito. Sólo tenemos que pensar en la codificación de la ley: la fuerza del código penal estriba precidamente en su "citabilidad". Si la intervención de Freud quiere ser públicay oral, si "se imagina" como tal, se presenta no obstante como una intervención escrita. Hasta aquí, bien. Pero hay más en juego que la tensión entre diversos modos de expresión. Me refiero, claro está, al marco intelectual e institucional del discurso de Freud, al contexto académico (imaginario o no) de su intrvención, diferente pero también parecido al mío. Conviene tener en cuenta este parecido, por pálido que sea, ya que la dificultad con la que yo estoy luchando no es sólo la "homosexualidad en sí" (como si hubiera tal cosa, o como si el problema de Freud fuera la "femenidad en sí"), sino también los límites de mi licencia para hablar o escribir sobre la homosexualidad y, más específicamente, sobre su relación con la actividad literaria. Lo que más me concierne es la dificultad de dirigirme a "ustedes", los lectores, de modo equilibrado e igualitario; es la dificultad de interpelar a algunos más, o más problemáticamente, que a otros, y la dificultad de situarme a mí mismo, como hablante y escritor, en este acto enunciativo.

Urge aclarar lo que quiero decir con la interpelación. Según Louis Althusser, la interpelación es aquel acto que constituye al sujeto como sujeto ante la ley, como cuando un agente o representante de la ley, por ejemplo un policía, grita "¡oiga, usted!” o “¡oye,

${ }^{3}$ Según Althusser, 'l'idéologie 'agit' ou 'fonctionne' de telle sorte qu'elle 'recrute' des sujets parmi les individus (elle les recrute tous), ou 'transforme' les individus en sujets (elle les transforme 
tú!". ${ }^{3}$ Althusser describe la interpelación en términos no sólo de sujeción sino también de reclutamiento y transformación. Las implicaciones nacionalistas y militaristas saltan a la vista, pero la interpelación no se limita, ni mucho menos, a las llamadas fuerzas del orden, sea el ejército o la policía. En su conceptualización de los aparatos ideológicos del estado, los agentes de la interpelación pueden abarcar a políticos, religiosos y académicos. Teóricos posteriores han extendido la interpelación al cine, la televisión, y otros artefactos de la comunicación, pero también han señalado que la teoría de Althusser subestima las posibilidades de resisiencia y desobediencia. ${ }^{4}$ Judith Butler, por ejemplo, examina las peripecias de la desobediencia, desde mantener el silencio y negarse a responder hasta lo que ella llama "la vivencia paródica de la conformidad", es decir, la posibilidad de(re)transformar, aunque sólo sea fugaz y parcialmente, la transformación supuestamente efectuada por el poder, la posibilidad de resistir alguna instancia del poder al responder "¿quién, yo?", o incluso "¿sí?", a la llamada "¡oye, tú” (122). Quisiera dejar sobre la mesa la variedad de respuestas posibles, pero también quisiera considerar - siguiendo la línea abierta por Butler - cómo los actos y agentes de la interpelación pueden ser no-oficiales o sólo marginalmente oficiales. Es decir, quisiera considerar cómo la interpelación, así como sus repercusiones éticas y políticas, puede extenderse a los homosexuales, no sólo como sujetos interpelados sino también, y de manera más interesante, como sujetos que interpelan, e intentan así sujetar, si no "reclutar" y "transformar", a otros también. ${ }^{5}$

Los sujetos homosexuales que interpelan pueden ser, desde luego, los homosexuales de clase media (y alta) de que habla José Joaquín Blanco y que consiguen o aspiran a conseguir "un trato policíaco preferencial" "no por justicia sino por la capacidad de nuestros bolsillos" (186); pero también pueden ser bastante menos "privilegiados" o, lo que es incluso más complicado, su "privilegio" puede ser nada menos que su persecución. ${ }^{6}$ Tal es

tous) par cette opération très précise que nous appelons l'interpellation, qu'on peut se représenter sur le type même de la plus banale interpellation policière (ou non) de tous les jours: 'hé, vous, là-bas!"” (126). Esto, sin embargo, no quiere decir que "el individuo" exista como tal antes de (o fuera de) la interpelación. Como dice Althusser, "les individus sont toujours-déjà des sujets. Donc les individus sont 'abstraits' par rapport aux sujets qu'ils sont toujour-déjà" (128, subrayado original).

${ }^{4}$ Para lecturas críticas de Althusser, véanse Jay y Geras. Para una apreciación de la influencia de Althusser en el cine, véase el libro de Lapsley y Westlake.

${ }^{5}$ El lugar de la enunciación, desde dónde se interpela, se verá "marcado", pues, como un lugar cuyo "poder" es de orden ético-político.

"El "privilegio" de la persecución corre a lo largo del ensayo de José Joaquín Blanco y, dicho sea de paso, de muchos otros también. "Mi tesis", escribe Blanco, "aun bastante vaga, es que los homosexuales mexicanos de hoy - no necesariamente los de ayer ni los de mañana-, al sufrir las persecuciones, represiones, discriminaciones del sistema intolerante, necesariamente estamos viviendo una marginalidad que además de su joda tiene sus beneficios: los valientes beneficios del rebelde, que no son intrínsecos a opción sexual alguna sino a una opción política: la lucha que nos cuesta sobrevivir ha dado hermosas razones y emociones a nuestras vidas, y sería una tragedia perderlas a cambio de la tolerancia del consumo" (185). Si bien es importante recalcar los aspectos económicos de la represión y opresión, Blanco corre el riesgo de romantizar la persecución. El privilegio de la persecución, ¿no lo será quizás sobre todo a los ojos de los homosexuales de clase media y alta que "ven", desde cierta distancia nostálgica, los beneficios del rebelde? 
el caso, como veremos, del protagonista, preso y perseguido, de una novela corta de Arenas. De todas formas, antes de llegar a ésta y otras obras, quisiera dejar la siguiente pregunta, como las plumas con las que he comenzado, flotando en el aire: ¿qué está en juego cuando un homosexual interpela - sea por escrito o con la voz- no ya a un heterosexual sino a un homosexual, a "otro" homosexual como si el sexo fuera la única "clase" que importara, como si el "otro" homosexual fuera el mismo que el sujeto homosexual que lo interpela?"

Ahora bien, mientras Freud interpela a los hombres como prójimos y cómplices y a las mujeres como problemas que estudiará, mientras articula una división entre él como sujeto académico y la feminidad como objeto académico, yo no les haré pensar que hay una división tan clara entre la homosexualidad como objeto académico y yo como sujeto académico. Lo que es más, mi decisión de limitarme a la homosexualidad masculina es estratégica, en la medida en que una de las cosas sobre las que quiero reflexionar es precisamente cómo se implica el sujeto en su objeto de discurso, de estudio, e incluso de creación estética. Después de todo, el deseo de saber quién es quién, el deseo de saber cómo lo que uno dice se relaciona con lo que hace, está conectado con la tendencia - extendida y problematizada en la crítica y la teoría contemporáneas tanto en los Estados Unidos como en gran parte de América Latina - a medir la actividad crítica sobre la base de la experiencia personal. No repetiré las diversas razones que se han aducido para cuestionar semejante base experiencial, pero sí que sería ingenuo descontar la persistencia del concepto de la experiencia. Un homosexual que habla o escribe sobre la homosexualidad bien puede resistir la esencialización de la experiencia, pero la experiencia, incluso si la ponemos entre comillas como lo hace la historiadora Joan Scott, no deja de imponerse como un problema. No obstante, este problema de la experiencia es tal que no pretendo llegar, ni mucho menos, a la verdad sobre la homosexualidad, incluso si me limitara, yo como sujeto norteamericano, a textos y contextos norteamericanos. Me apresuro a añadir que el acto de llamarme o de presentarme como "norteamericano" y "homosexual" no es auto-evidente, como tampoco lo es el discurso experiencial a que dicho acto pertenece.

A "decir verdad", nadie puede llegar a la verdad de modo total y definitivo; tampoco hay un escritor, o lector, o hablante ideal, sobre todo cuando lo ideal se concibe como un asunto de la experiencia real. Escéptico de los que afirman haber llegado o poder llegar a la verdad, pienso sin embargo que podemos, incluso tal vez debemos, tener en cuenta el juego de los "efectos de la verdad". Un aspecto de este juego es el hecho de que la sexualidad y la nacionalidad siguen empléandose, pese a tantas reservas y rectificaciones críticas, no sólo como marcas de experiencia sino también como señas de identidad. Si yo me he llamado, si yo me he interpelado a mí mismo como norteamericano y homosexual, si yo he asumido cierta interpelación anterior, no es para quedarme allí: como si esto constituyera parte de una experiencia unitaria y de una identidad sólida, y como si la conjunción de estas señas -nacionales y homosexuales - no fuera altamente conflictiva. De hecho, una de las cosas

\footnotetext{
${ }^{7}$ Parte del problema aquí es, sin lugar a dudas, el circuito de la interpelación: si un homosexual - un sujeto homosexual previamente interpelado por la instancia del poder que fuera - interpela a "otro" homosexual es porque le ha "identificado" como tal, le ha "asimilado" si no "reclutado" a la categoría "homosexual".
} 
que hay que señalar, junto con el peligro de reificar la nacionalidad y la sexualidad, ${ }^{8}$ es que el discurso nacional se resiste —en una nación tras otra, incluso en un proyecto nacional tras otro- a "justificar," y mucho menos a "celebrar" la homosexualidad.

El discurso nacional y nacionalista, necesariamente diferente de un país a otro, evidencia sin embargo ciertos rasgos bastante comunes: a saber, la tendencia a alimentarse de un vocabulario "familiar" y, por implicación, biológicamente "natural". La patria -y este híbrido interesante, la madre patria - es sólo el ejemplo más palmario, pero la producción de la nación está "íntimamante" ligada a nociones harto convencionales de la reproducción sexual. Aquí la posición o situación del homosexual es todo menos sencilla. Oscar Montero ha estudiado el anti-homosexualismo en el discurso nacional de Cuba en el siglo XIX y Arnaldo Cruz-Malavé en el discurso nacional de Puerto Rico en el siglo XX. Lo que estos y otros estudios - la mayoría de ellos fuera del ámbito hispano- indican es que si el homosexual es interpelado por el Estado, o por el proyecto del Estado, es con gran frecuencia menos como ciudadano actual o potencial que como problema o cuestión (la situación de las mujeres, históricamente hablando, presenta unos paralelismos importantes). Esto no quiere decir, ni mucho menos, que los homosexuales no funcionen dentro del sistema estatal, que no lo puedan apoyar, o que no contribuyan a su perpetuación. Como dice José Joaquín Blanco, con respecto a México, "[n]o somos, ni con mucho, los patitos feos del sistema: estamos bien metidos en él, y si hemos de ser honestos, reconoceremos que en la mayoría de los casos somos más cómplices de nuestra clase ... que solidarios de los jodidos, incluso de los homosexuales jodidos" (185).

Volveré a cuestiones de solidaridad y complicidad. Mientras tanto, quiero repetir que si la sexualidad y la nacionalidad funcionan como efectos de la verdad, no se trata simplemente de superar o abandonar estos efectos, como si parte de lo que con ellos se construye no fuera precisamente una verdad, o una identidad, que se niega a ser reducida a la construcción y, por ende, a la desconstrucción. Dicho esto, conviene recordar que, incluso cuando apuntan hacia algo "esencial" o "natural," son efectos de la historia.' Como señala Elaine Showalter, "la palabra 'homosexual', fue acuñada por el escritor húngaro, Karoly Benkert, en 1869, y entró en el inglés cuando la Psychopathia Sexualis de KrafftEbing fue traducida en los 1890" (171). ${ }^{10}$ Su aparición en el español sería bastante similar. Es interesante notar que, como palabra, "homosexual" precede a "heterosexual", un dato histórico que da lugar a un juego bastante delicioso con la suplementariedad. De todos modos, la acepción moderna de "homosexual" está fuertemente ligada a un aparato psicomédico de detección y clasificación, disciplina y castigo, de acuerdo con lo que David Greenberg ha llamado la "medicalización de lahomosexualidad"(400). Michel Foucault, más notoriamente, ha recalcado la condición moderna de la "homosexualidad" ( $y$ de la "heterosexualidad") de forma tan persuasiva que muchos se han visto obligados a acreditar

\footnotetext{
${ }^{8}$ El peligro de reificar y esencializar la nacionalidad y la sexualidad consistiría en desnudarlas de toda contingencia histórica y caer en el solipsismo de la experiencia (yo soy yo; tú eres tú). Ahora bien, también existe el peligro de descartar la experiencia por completo: como si no hubiera ningún problema al hablar de los otros o, incluso, de uno mismo.

${ }^{9}$ La verdad misma es un efecto de la historia, de sus palabras y sus narraciones.

${ }^{10}$ Greenberg precisa que Benkert creía en el "hermafroditismo psíquico" (409).
} 
o a desacreditar no sólo la validez del término, sino también la realidad de una existencia "homosexual" a través de los siglos. ${ }^{11}$ Es interesante notar, aunque sólo sea de pasada, que el trabajo de Benedict Anderson, en el que se subraya la condición moderna de la "nacionalidad" y el nacionalismo, ha tenido repercusiones parecidas. ${ }^{12}$

De todas formas, la crítica de la reificación, la esencialización y la naturalización de la identidad y la experiencia es especialmente compleja en el caso de la homosexualidad, ya que las experiencias e identidades en cuestión muchas veces han sido naturalizadas como no naturales e incluso anti-naturales. Esta crítica, de signo claramente foucauldiano, ha generado una diversidad de reacciones, entre ellas la decisión por parte de algunos de correr el riesgo del esencialismo y de "recuperar" una historia del deseo homosexual (algo parecido parece válido para lo que se podría llamar el deseo nacional). ${ }^{13}$ La palabra "homosexual" es, como ya he indicado, en sí misma un problema, ya que su posición en un dispositivo médico-legal la marca como un término de complicidad. Si yo sigo usando "homosexual", no es porque descarte su historia institucional, sino precisamente porque es problemático en un sentido menos definido por cierta hegemonía anglo-americana.${ }^{14}$ No se trata, con esto, de rechazar el valor estratégico de palabras como "gay" o "queer" en determinados contextos; lo que sí se debe apuntar, sin embargo, es que este valor no está desprovisto de presuposiciones nacionales, o al menos culturales, que tanto Arenas como Goytisolo, aunque de maneras diferentes, reiteran y resisten.

Ser "gay" en Cuba o en México o hasta en España no es lo mismo que ser "gay" en los Estados Unidos (como si esto último fuera, dicho sea de paso, algo realmente unitario). En México, como señala Ian Lumsden, llamarse o ser llamado "gay" es una cuestión no sólo de aceptación social y protección legal, sino también de la situación cultural, racial y económica del sujeto (de nuevo, se puede decir lo mismo de partes de los Estados Unidos). La palabra "gay" o "gayo" o "gai" es una importación o imposición relativamente reciente y se encuentra más en aquellas comunidades que lindan con los Estados Unidos-los espacios fronterizos de Gloria Anzaldúa - y en aquellas zonas urbanas caracterizadas, para bien o para

"Foucault hace una distinción entre lo que se podría llamar "actos indiscretos" e "identidades discretas". De acuerdo con esta distinción, el sodomita es el efecto de actos sodomitas mientras que el homosexual es supuestamente la causa de actos homosexuales. O como lo estiliza, y dramatiza, Foucault, "le sodomite était un relaps, l'homosexuel est maintenant une espèce" (59). ${ }^{12}$ Tanto Foucault, en su trabajo sobre la sexualidad, como Benedict Anderson, en su trabajo sobre la nacionalidad, apuntan al fin del siglo dieciocho como el comienzo de un período de indagación especialmente intensa en el deseo y el patriotismo, un momento, un tanto difuso, cuando la sexualidad y la nacionalidad, secularizadas y administradas, se imponen. Doris Sommer ya ha notado estas conexiones, fijándose en el llamado "romance" heterosexual en América Latina. Propongo algo similar, aunque desde luego diferente, al reflexionar sobre la homosexualidad dentro de un marco internacional en el que la nacionalidad es simultanéamente mantenida y abandonada, refinada y distorsionada.

${ }^{13}$ Para la cuestión del esencialismo véanse Fuss (21), Jardine (58) y Heath (99).

${ }^{14}$ Bergmann y Smith (11) se refieren a Oscar Guasch, quien rechaza tanto "homosexual" como "gay" como ajenos al español para quedarse con el verbo "entender". 
mal, como cosmopolitas. ${ }^{15}$ La palabra "gay" connota, entre otras cosas, cierto contacto con vocabularios y prácticas norteamericanos, sobre todo en América Latina. "Gay", como dice Lumsden con respecto a México, y Arenas con respecto a Cuba, no simplemente resiste o socava los trucos o estratagemas institucionales que resuenan, incluso hoy, en el término "homosexual", sino que construye por sí misma una pequeña institución, conllevando a veces un sentido de algo norteamericano.

No quiero decir por ello que haya que abandonar todo uso del término "gay" en favor, por ejemplo, de algo "auténticamente" latinoamericano (como si el discurso de la autenticidad, con su invocación de algo puro y completo no fuera igualmente inquietante, o como si América Latina constituyera un todo homogéneo y coherente); tampoco quiero decir que todos aquellos latinos o latinoamericanos que se llaman "gay" sean, de alguna forma, menos latinoamericanos (aunque ésta dista mucho de ser, como veremos, una percepción insignificante); pero sí quiero decir que la palabra "gay" debería entenderse dentro de un marco internacional sumamente complejo. En el argot mexicano, por ejemplo, "gay" o "gayo" es uno de varios términos que incluyen "vestida" (o sea, asumir en público una conducta supuestamente femenina o afeminada), "mayate" ("macho" o "machín"), e "internacional". ${ }^{16}$ Este último término es interesante: porque para ser "internacional" el sujeto tiene que contravenir una demarcación supuestamente nacional que afirma que la posicionalidad sexual es constitutiva de la identidad sexual. Ser "internacional" significa, en otras palabras, ser a la vez "activo" y "pasivo," o como dicen ciertos antropólogos, "insertivo" y "receptivo"; significa "dar" y "recibir" el falo por partes iguales, ser tanto el "dante" como el "tomante" en el acto sexual. Para ampliar la famosa distinción de Octavio Paz es "chingar" y ser "chingado" a la vez. ${ }^{17}$ No es de sorprender, pues, que, como ya he sugerido, se le considere más, menos, y otro que mexicano.

${ }^{15}$ Evidentemente no sólo la palabra "homosexual" sino también la palabra "gay" o alguna variante suya se dan en castellano también. Como explica Antoni Mirabet i Mullol, “[e]l término 'gay' es un adjetivo de origen provenzal, que pasó al catalán (gai), al francés (gai) - y de éste al inglés (gay) al castellano (gayo), al galaico-portugués (gaio) y al italiano (gaio). Tiene diferentes significados: alegre, divertido, festivo, simpático, ufano, satisfecho, jovial, jocundo, contento, brillante, bien vestido, atractivo, fresco, disoluto, inmoral, calavera, de vida festiva o disipada, impertinente, prostituto, etc. Además en los países anglosajones se aplica también esta palabra, como adjetivo y como sustantivo, a los homosexuales. ... Gay es el homosexual que se reconoce como tal' (333, subrayado original).

${ }^{16}$ Como dice Lumsden, el término "internacional" indica que papeles sexuales intercambiables no son indígenas en México (24). Para más sobre el léxico (homo)sexual en el Caribe y América Latina, véanse Murray y Arboleda (139) y Murray y Dynes (180).

17 La comprensión de la homosexualidad en términos de pasividad y actividad delata una misoginia bien arraigada. Como dice Octavio Paz, "toda mujer, aun la que se da voluntariamente, es desgarrada, chingada por el hombre. En cierto sentido todos somos, por el solo hecho de nacer de mujer, hijos de la Chingada, hijos de Eva. Mas lo característico del mexicano reside, a mi juicio, en la violenta, sarcástica humillación de la Madre y en la no menos violenta afirmación del Padre (72). La formulación de Paz — basada en "lo característico"— no deja de ser debatible, pero la conexión que se deja traslucir entre la misoginia y la homofobia, ambas concebidas y "caracterizadas" en términos de pasividad, no debe ignorarse. Eve Sedgwick, dentro de otra "tradición", afirma que "la homofobia, dirigida por hombres y en contra de [otros] hombres, es misógina" (20). 
El "estatus" nacional del homosexual como "chingado", como recipiente y no como fuente del poder masculino, es, como mínimo, precario. Pero el "estatus" nacional del llamado "internacional" es tal vez incluso más precario. La mobilidad del "internacional" va en contra de una dinámica sexual que se extiende a través de gran parte de América Latina, incluyendo México, Cuba y Nicaragua. Según Roger Lancaster, en su estudio sobre el machismo en Nicaragua, "la norma anglo-americana sería la que sigue: un hombre adquiere importancia sexual y honor entre otros hombres mediante, y sólo mediante, sus 'transacciones' con mujeres. Los homosexuales parecen rechazar tal sistema. En Nicaragua, [en cambio] ... [un] hombre adquiere importancia sexual y honor entre otros hombres mediante su [llamado] rol activo en la relación sexual (que sea con mujeres o con otros hombres)" (250). ${ }^{18}$ Sólo el "cochón" o "maricón", la "reina" o "loca", es decir, el hombre que asume y exhibe "rasgos" femeninos, se ve "marcado", o, como dice Lancaster, "estigmatizado" en este sistema. ${ }^{19}$ De hecho, el "bugarrón" o "mayate", caracterizado por una conducta visible y convencionalmente masculina, no se encuentra necesariamente "estigmatizado" y puede incluso reforzar y aumentar su masculinidad al penetrar a otros hombres. Esto es crucial, ya que señala una diferencia en el modo de entender y experimentar la homosexualidad en una y otra cultura. Tan crucial es esta diferencia que el llamado "internacional" queda reducido, por algunos, a un sentido nacional, o cultural, que es en última instancia angloamericano.

Las conexiones entre identidad cultural y posicionalidad sexual se encuentran en las obras de diversos escritores literarios también. Juan Goytisolo profesa sólo haber tenido relaciones sexuales con hombres "heterosexuales que ocasionalmente pueden ser bisexuales" y que provienen de países no occidentales. ${ }^{20}$ Se resiste, como veremos, al movimiento gay y lesbiano y se queda con una versión bastante idealizada y exoticista de la homosexualidad en el mundo islámico. Pero si Goytisolo indica que está fuera de lugar en Europa, Reinaldo Arenas, en su autobiografía Antes que anochezca (1992), profesa hallarse fuera de lugar en los Estados Unidos. Dice Arenas, "después, al llegar al exilio [en los Estados Unidos], he visto que las

\footnotetext{
${ }^{18}$ Leiner y Salessi hacen observaciones semejantes con respecto a Cuba y Argentina respectivamente. Según Leiner, "tener relaciones sexuales con otro hombre no es lo que le identifica a uno como homosexual [en Cuba]. Para muchos cubanos, un hombre es homosexual sólo si asume una postura pasiva y receptiva. Y se le sospecha de ser homosexual sólo si su comportamiento no es macho: si no muestra interés en juegos fuertes, o si no es físicamente fuerte y musculoso"(22). Y según Salessi, aquellos hombres "que no invertían el papel activo e insertivo considerado el papel correcto de su sexo biológico ... no estaban 'marcados' más que como hombres" (367).

${ }^{19}$ Hace falta matizar la aseveración de que sólo el homosexual visiblemente "pasivo" se halla "estigmatizado". Como señala Oscar Montero, "pederastas activos" en la Cuba del siglo pasado (y presente) también se veían como objetos de preocupación, control y rechazo sociales (104).

${ }^{20}$ Goytisolo le dice a Escudero que, "de la gente que yo sabía que eran homosexuales que conocía en Nueva York creo que han muerto todos. Ha sido una hecatombe. Por fortuna he sido siempre muy selecto. Nunca he tenido ambigüedad con europeos. Sólo me ha interesado lo que yo llamo la zona sotádica y nunca me he acostado con homosexuales sino con heterosexuales que ocasionalmente pueden ser bisexuales. Entonces, esto yo creo que en cierto modo me ha salvado de la hecatombe.... Me costó mucho hacer la primera prueba. Realmente no sabía si había cometido algún error" (132).
} 
relaciones sexuales pueden ser tediosas e insatisfechas [sic]. Existe como una especie de categoría o división en el mundo homosexual; la loca se reúne con la loca y todo el mundo hace de todo. Por un rato, una persona mama y luego la otra persona se la mama al mamante. ¿Cómo puede haber satisfacción así? Si, precisamente, lo que uno busca es su contrario. La belleza de las relaciones de entonces era que encontrábamos a nuestros contrarios; encontrábamos a aquel hombre, a aquel recluta poderoso que quería, desesperadamente, templarnos" (132). Éste es un retrato impresionante del placer y la belleza; porque a diferencia de lo que hace, por ejemplo, José Joaquín Blanco, lo que Arenas critica no es la mercantilización del erotismo bajo el capitalismo (o en palabras de Blanco, "el negocio de la tolerancia sexual", 184), sino más bien la aparente falta de oposicionalidad en las relaciones sexuales entre hombres en los Estados Unidos.

Lejos de satisfacerse con una reversibilidad sexual en la que papeles y posiciones se borran, Arenas se muestra nostálgico de las condiciones del sexo en Cuba. En la medida en que estas condiciones incluyen encuentros furtivos con reclutas, guardas y otros militares poderosos, con los mismos hombres ocupados en el control de las "locas", Arenas declara que son difíciles de reproducir en los Estados Unidos. Sin duda, hay más que una pizca de ironía aquí; porque estas condiciones, las reglas disciplinarias establecidas por el régimen revolucionario contra los homosexuales (y los escritores) son precisamente lo que motiva la huida de Arenas de Cuba. Lo que no se puede sufrir en Cuba es, en los Estados Unidos, el objeto mismo de la añoranza y el deseo. ${ }^{21}$ Semejantes generalizaciones son, sin duda, peligrosas; operan como si la división, u oposición, entre el norte y el sur fuera absoluta. Después de todo, pueden encontrarse algunos papeles bastante rígidos en los Estados Unidos y algunas prácticas bastante fluidas en Cuba, México y Nicaragua. No obstante, el que diferencias nacionales o culturales se invoquen por vía de la homosexualidad de modo tal que incluso lo "internacional" lleva una marca nacional debería hacernos vacilar. Como mínimo, debería hacernos conscientes de la carga ideológica de las palabras y de las vidas, prácticas, e identidades que estas palabras, aunque insuficientemente, designan.

El marco internacional, por problemático que sea, es aquí necesario precisamente porque la nacionalidad ha sido, y en gran modo sigue siendo, inseparable de la heterosexualidad. La idea del "romance" heterosexual como fundamental, o fundacional, para la nacionalidad se actualiza, una y otra vez, en el control, persecución y restricción de los homosexuales, en su poco inocente educación, terapia y conversión, en su exclusión de opciones militares, matrimoniales y familiares. ${ }^{22}$ Además, se ha visto a los homosexuales como negando el valor de la reproducción biológica, se les ha visto como improductivos, más proclives al derroche y la disipación que a la creación y generación sociales: es decir, como frenos a la perpetuación y expansión de los proyectos nacionales. Se les ha visto, además, como atrapados en una lógica homogénea, incapaces de apreciar la diferencia y por lo tanto

${ }^{21}$ Cabrera Infante también señala estas "contradicciones" en la vida y obra de Arenas. Véase el apartado sobre Arenas en Mea Cuba. El problema, aquí y en otros lugares, es que el homosexualismo se pinta en términos masoquistas. Para Freud, el masoquismo es un rasgo distintivo de las mujeres y de los homosexuales: uno se pregunta qué está en juego en semejante generalización, qué poder se guarda, qué conducta se racionaliza. Véase el ensayo de Freud sobre el masoquismo.

${ }^{22}$ Véase el estudio, antes mencionado, de Doris Sommer. 
incapaces de trascender el yo aislado y de "contribuir a la sociedad" mediante el trabajo que tanto el capitalismo como el comunismo, a pesar de sus diferencias, valorizan. También se les ha visto como penosamente susceptibles a la seducción, y, por extensión, a la traición y la infidelidad. ${ }^{23}$ Con el sida, la idea del homosexual como una amenaza a la integridad nacional cobra un tono todavía más mórbido y sombrío, inspirando ideas de reclusión obligatoria, clasificación, vigilancia y hasta tatuajes identificatorios. Estas visiones son, en parte, las que se encuentran en muchas obras de Goytisolo y Arenas, visiones que ellos re-presentan y alteran dentro de un panorama de opresión y resistencia.

Dentro de este panorama, los problemas de terminología sexual y nacional, de "homosexual", "gay", "internacional", etc., pueden parecer superfluos: pero sólo si olvidamos cómo funcionan estos términos a modo de señas de identidad, cómo pueden ser, ellos mismos, cual tatuajes o medallas de honor; cómo pueden controlarnos y cómo pueden ayudarnos a resistir. Ahora bien, al hablar en plural, estoy dando por sentada una cuestión importante, una cuestión que me hace volver a mi apropiación irónica de Freud. La interpelación freudiana a las mujeres como el problema sobre el que hablará es, como ya he sugerido, problemática también. Plumas o no, no se trata de un problema que me tome a la ligera. Al repetir el gesto interpelativo de Freud en un registro diferente, interpelando a los homosexuales como el problema, quiero subrayar la importancia de la interpelación para la constitución, consolidación y diseminación de las identidades. Y junto con la cuestión de la interpelación, quiero enfatizar la significación del lugar de la enunciación, el lugar desde el que uno habla. Porque si he designado a algunos de nosotros como el problema, ha sido también para designar el problema como "nosotros" mismos. Es decir que el problema es precisamente el "estatus" o el "estado" del "nosotros", sus inclusiones y exclusiones, sus movimientos y sedimentaciones, sus brechas y cerrazones. Es por esta razón que la literatura, en la medida en que pone en primer plano cuestiones de interpelación y enunciación, puede prestar un servicio especial: para algunos de nosotros, de nuevo de manera problemática, tal vez incluso más que para otros.

ENTRE LA SOLEDAD Y LA SOLIDARIDAD

Ante todo tenés que pensar en agruparte, en no quedarte solo, eso seguro te va a ayudar Manuel Puig, El beso de la mujer araña

Quiero referirme, brevemente, a un par de textos en los que la cuestión de la interpelación y la enunciación se enfoca en el llamado "problema" de la homosexualidad. Ambos textos problematizan, junto con este otro problema, la nacionalidad. El primer texto es Arturo la estrella más brillante (1984) de Reinaldo Arenas y el segundo es Paisajes después de la batalla (1982) de Juan Goytisolo. Me centraré en el primero, pero quiero apuntar que

${ }^{23}$ Esta percepción es parodiada por Senel Paz: "Siempre hay que estar alertas: los maricones son traidores por naturaleza, por pecado original" (46). La obra de Paz ha sido leída como "prueba" de que la política sexual en Cuba ha cambiado bastante y, por otro lado, que no ha cambiado tanto. Véase el artículo equilibrado de Emilio Bejel. 
ambos textos, el primero escrito por un cubano, el segundo por un español (aunque promocionado por muchos escritores y críticos latinamericanos como un "compa-ñero de viaje"), ${ }^{24}$ pugnan con los espacios de la escritura, con la incitación al discurso, ${ }^{25}$ y con los avatares del sujeto y el objeto, el yo y el otro. Ambos textos juegan con la autobiografia, sus añagazas y sus posibilidades. Sin pretender arraigar los textos en una verdad biográfica, creo que es importante notar que Arenas, un escritor abiertamente homosexual, sufre persecución e internamiento bajo Castro, huye de Cuba en 1980 en el éxodo de Mariel, y, padeciendo del sida, se suicida en los Estados Unidos en 1990. Goytisolo es asímismo un escritor en el exilio (aunque de muy otra índole), que abandona España bajo Franco y que divide su tiempo entre París y Marraquech. Goytisolo es también homosexual, o acaso bisexual, ya que está casado y hace repetidas, aunque esporádicas, referencias a su esposa, la escritora Monique Lange. Con todo, Goytisolo ha hecho pública, una y otra vez, su fascinación erótica con hombres árabes y turcos, e incluso ha declarado que no teme el sida porque jamás ha tenido "ambigüedad" con europeos. ${ }^{26} \mathrm{He}$ comentado, en otro lugar, lo absurdo que es la autoproclamada capacidad de Goytisolo para limitar el sida a homosexuales europeos, pero merece la pena insistir en cómo la nacionalidad y la sexualidad se imbrican hasta en su concepción de la enfermedad. ${ }^{27}$ Aquí quisiera, sin embargo, fijarme en algo un poco diferente.

En el texto de Arenas y, aunque de manera más sutil, en el texto de Goytisolo, la escritura y la homosexualidad se presentan como problemas para un proyecto revolucionario de ámbito a la vez nacional e internacional, un proyecto que interpela a los sujetos de formas divergentes pero relativamente espécificas. Ambos escritores se refieren a la revolución cubana y a la persecución y reclusión de homosexuales en campamentos de trabajo forzado, las Unidades Militares de Ayuda a la Producción o UMAP, en $1965 .{ }^{28}$ Los campamentos constituyen el lugar de la enunciación del protagonista de Arturo, la estrella más brillante y el sujeto a quien interpela es, ante todo, su amante ausente e imaginario. La historia de Arturo se relata, sin embargo, en tercera persona y presumiblemente fuera del campamento, un hecho que hace que el lugar de la enunciación se aproxime, aunque nunca del todo, al del propio autor (una nota explicativa por el propio Arenas sólo refuerza esta percepción). ${ }^{29}$ Las UMAP también figuran en diversos textos de Goytisolo, en especial Las virtudes del pájaro solitario y En los reinos de taifa. En Paisajes después de la batalla, no figuran los campamentos, pero sí las preocupaciones políticas, estéticas y epistemológicas de la revolución: si bien, como veremos dentro de poco, de manera bastante curiosa. En Paisajes, el lugar de la enunciación es el apartamento en París del protagonista, narrador, o autor implícito y el sujeto a quien

\footnotetext{
${ }^{24}$ Véanse, por ejemplo, el libro de Carlos Fuentes y los artículos de Luce López Baralt y Cabrera Infante.

${ }^{25}$ Este concepto proviene de Foucault; véase La volonté de savoir (25-49).

${ }^{26}$ Véase, de nuevo, la entrevista con Javier Escudero.

${ }^{27}$ Véase mi libro sobre Goytisolo, de próxima aparición (371-372).

${ }^{28}$ La persecución de los homosexuales en Cuba ha suscitado reacciones bien diversas. Para una crítica (o ataque) del régimen véase Young; para una crítica (o defensa), véase Rich y Argüelles.

${ }^{29}$ Según explica Arenas, Arturo está dedicado a Nelson Rodríguez Leyva, un homosexual que murió al intentar "desviar de su ruta a un avión de Cubana de Aviación, rumbo a la Florida" (93); y "[e]n cuanto a los originales de este relato, escrito en La Habana en 1971, pueden ser consultados en la biblioteca de la Universidad de Princeton, New Jersey" (94).
} 
interpela es, en gran medida, él mismo, aunque es verdad que el uso de la segunda persona singular provoca necesariamente algunos efectos de complejidad y complicidad vertiginosos. Un efecto es no saber a veces quien interpela — o se dirige - a quien. Con todo, resulta bastante claro que, sea quien sea el que ocupa el lugar de la enunciación, éste es interpelado a su vez por diversas instancias del poder. Pero hay algo más. Como Arturo, también el sujeto del texto de Goytisolo es interpelado no sólo por el poder estatal y los representantes y portavoces de sus aparatos ideológicos sino también por otros que a primera vista parecen carecer de poder, entre ellos otros homosexuales. Sin querer insistir en la función del autor, creo que se puede decir que ambos Arenas y Goytisolo se hallan implicados, consciente y ambiguamente, en sus textos; ambos designan su lugar de enunciación como conflictivo; y ambos indican cómo la interpelación dista mucho de ser sencilla y universal.

En Arturo, la estrella más brillante, Arenas, o más bien Arturo, subraya el propio acto de escribir. Al robar tiempo para escribir en un campamento al que ha sido confinado por "conducta impropia", es decir, por ser homosexual, Arturo pone en evidencia lo que está en juego, políticamente hablando, en determinados "estilos" de amar. El encarcelamiento, el trabajo obligatorio y otras formas de servidumbre involuntaria proporcionan aquí, paradójicamente, la ocasión para una creatividad prolífica. Con el fin de que esta creatividad no parezca fácil y tranquila, opcional o accidental, Arenas presenta la escritura de Arturo como un acto absolutamente vital: "decidió que para salvarse tenía que comenzar a escribir inmediatamente" (42). Con su propia salvación en juego, Arturo emprende una escritura a la vez furtiva y furiosa. Con urgencia, escribe: en cualquier lugar y en todos los lugares imaginables, pero sobre todo en "las contratapas, los respaldos, los márgenes y forros de los manuales de marxismo leninismo y de economía robados de la Sección Política ... [en] los márgenes de los grotescos carteles políticos instalados en las paredes y murales ... del campamento" (44). Es un emborronador de cuartillas incansable, cubriendo un documento socio-político con las rayas y rasguños de su identidad. Al hacerlo, Arturo complica los mensajes claros y concisos de los manuales y los carteles políticos, reescribe la interpelación oficial de sujetos nacionales y sexuales "apropiados," y carga estos escritos con algo críptico y casi ilegible. En contra de aquella autoridad, centrada y recta, se encuentra esta otra autoridad: marginal, invertida y tortuosa.

La autoridad de Arturo, tal vez la de Arenas, es, como he dicho, profundamente conflictiva. apresurado, paranoico, errático, tiene lugar, literalmente, en el material impreso de otros, otros cuya autoridad es aquí la del Estado. Escritos particulares y privados como los diarios se ven descalificados como "cosa de maricones" y, por tanto, como fruto de una identidad interpelada e identificada, reconocida y castigada, como anti-social y egoísta. La homosexualidad parece empapar esta escritura íntima, pero es un efecto tanto del Estado como de un yo aislado, un efecto impuesto, en parte, desde fuera y asumido, aunque con diferencias notables, desde dentro. ${ }^{30}$ La escritura de Arturo es en muchos respectos una reescritura de la dificultad para escribir que experimenta el propio Arenas bajo Castro. De hecho, la escritura de Arenas se pierde, es secuestrada y destruida, repetidamente; sobre todo

\footnotetext{
${ }^{30}$ En Antes que anochezca, Arenas afirma que "creo que si una cosa desarrolló la represión sexual en Cuba fue, precisamente, la liberación sexual. Quizá como una protesta contra el régimen, las prácticas homosexuales empezaron a proliferar cada vez con mayor desenfado" (107).
} 
hacia el final de su vida, mucha de su obra se reproduce de memoria, se editada apresuradamente, y se publica póstumamente. Portando las huellas de la autobiografia, sus obras son ensayos de auto-inscripción donde el yo está imbricado en la alteridad.

El otro es el objeto del deseo de Arturo, pero el otro es también, en parte, el Estado, el mismo Estado que designa a los homosexuales como "otros", que los agrupa y los aísla supuestamente para reintegrarlos a la sociedad. Al hacer de los documentos oficiales del Estado, tanto administrativos como militares, el espacio de algo pródigo y lujoso, al rellenar los márgenes y casi borrar el centro con vocablos de una riqueza extravagante, al describir su escritura como prolífica, furtiva, periférica y parásita, Arturo se presenta, aunque inconscientemente, como el autor de otro estado, otra nación, una nación que, sin embargo, no es una. Todo esto puede parecer muy atractivo, al menos para los que desean un orden menos restrictivo, pero Arturo está lejos de ser un modelo de solidaridad resistente y su estado ideal es, como veremos, un estado bastante solitario. De hecho, describe, sin piedad, a los prisioneros que lo "acompañan" como locas chillonas, vulgares, débiles, e insoportablemente absurdas. Como si no bastaran los códigos y clasificaciones del Estado, Arturo emplea un sistema de clasificación en el que la alteridad, entendida negativamente, se divide en tres categorías distintas y jerárquicamente ordenadas. " $[\mathrm{H}]$ abía establecido tres categorías: ellos, los otros, y los demás" (13). ${ }^{31}$ "Los demás" son todos aquellos "buenos" cubanos que apoyan, por acto u omisión, el estado; "los otros" son los guardianes de la prisión, y por extensión del orden, aquellos reclutas y guardas cuyo poder es directo y coercitivo, que desean y sin embargo no los desean a "ellos", (los mismos hombres que Arenas recuerda nostálgicamente en su autobiografia); y "ellos", o mejor aun, "ellas", son los otros prisioneros, caracterizados por Arturo como "afeminados, artificiales, [y] grotescos" (12), "corrompiéndolo todo, hasta la auténtica furia del que padece el terror"(12). El destino de la autenticidad es crítico para la concepción que tiene Arturo, si no Arenas, de la libertad y creatividad individuales, una concepción que choca no sólo con la colectividad comunista sino con la solidaridad homosexual también. La verdad es que la celebración por parte de Arturo de la individualidad es tal que cualquier tipo de unidad puede parecer peligrosamente restrictivo, como si la manera en que es interpelado por los "maricones", los otros "maricones", fuera tan inaguantable como la manera en que es interpelado por el Estado. Contra "ellos", "los otros", y "los demás", sólo está él, el amante imaginario cuya aparición depende de la capacidad de Arturo para producir un mundo alternativo de belleza, creatividad, e invención, para realizar, imposiblemente, el hombre de sus sueños.

El individualismo exasperado de Arturo puede leerse como una respuesta al imperativo colectivo del régimen comunista, pero hay algo más. Es también el efecto de un poderoso dispositivo de identificación e interpelación que califica al homosexual de egocéntrico e hipersexual, incapaz de limitar el narcisismo ni de sublimar los lazos libidinales que, según Freud, son necesarios para la identificación con otros a través del líder. ${ }^{32}$ En otras palabras, la desobediencia de Arturo está, en parte, escrita, o pre-escrita, por el propio régimen, en la medida en que el régimen escribe, e interpela, a los homosexuales de narcisistas e

${ }^{31}$ El propio Arenas, en Antes que anochezca, también demuestra un afán clasificatorio y titula uno de los capítulos, "Las cuatro categorías de las locas" (103).

32 Véase Group Psychology de Freud. 
hipersexuales. ${ }^{33}$ Esta creación hipersexual y narcisista, promiscua y egocéntrica, se asocia además con cualquier forma de arte que valorice la experimentación, el juego, y el placer. La valorización, por parte del propio Arenas, de la investigación intelectual, la creatividad artística, y la práctica homosexual, todas ellas entretejidas como sus señas de identidad, puede leerse a la luz de diversas declaraciones de oficiales cubanos, a veces sutiles y a veces incendiarias, en las que se ligan la actividad artístico-intelectual y la "(in)moralidad sexual". Las famosas "Palabras a los intelectuales" de Castro en 1961 y, sobre todo, la "Declaración del Congreso Nacional de Educación y Cultura" de 1971, son claros ejemplos. ${ }^{34}$ En esta última, la homosexualidad se describe como una "desviación" y como un tipo de "patología social". ${ }^{35}$ Al rechazar la homosexualidad sobre la base de un "principio militante", el Congreso recomienda que se estudie más "este complejo problema", sin, no obstante, considerarlo "un problema central o fundamental en nuestra sociedad". ${ }^{36}$

Tal lenguaje resulta funcional en este contexto, ya que permite el descubrimiento, vigilancia y control de los homosexuales sin implicar, supuestamente, al sistema político en su totalidad. Si bien puede que se logre este propósito, huelga decir que aunque el "carácter antisocial" de la homosexualidad no sea un problema central o fundamental para "nuestra" sociedad, sigue siendo un problema decididamente más central y fundamental para los homosexuales mismos. Ahora bien, tan pronto como el homosexual confronta el "ioye, tú!", de la interpelación y reconoce que es, él mismo, el problema, surge el espectro del narcisismo y la obsesión sexual. Interpelado por el régimen revolucionario como problemático y marginado, el sujeto homosexual se enfrenta a los límites de "nuestra" sociedad, reconoce la exclusividad de este "nosotros" al reconocerse, al reconocer su "yo", como excluido. Aquí lo sexual es, sin duda alguna, político. De ahí que este yo (homo)sexual sea el efecto, en parte, del mismo sistema que lo sujeta a un programa disciplinario de educación, producción y correción. Paradójicamente, todo intento de defenderse o justificarse incluso, si no especialmente, cuando se emprende en nombre de una comunidad "menor" o "alternativa"- puede interpretarse como una defensa o justificación del "yo", del sujeto sexual supuestamente reñido con el sujeto nacional.

El homosexual, debidamente repudiado, es el ab-yecto del pro-yecto revolucionario. El postulado subyacente es relativamente antiguo, y se encuentra una y otra vez en la confluencia de la decadencia literaria y literal, en la corrupción desenfrenada de la palabra y del cuerpo. Para la imaginación revolucionaria, el placer del texto, dado a la disipación y a la diseminación improductiva, refleja el placer de la carne y lo amplía, bastante paradójicamente, como la amenaza de un narcisismo sexual generalizado: después de todo, no es posible ensimismarse en los juegos del significante sin apartarse, aunque sólo sea

\footnotetext{
${ }^{33}$ La percepción e interpelación de los homosexuales como narcisistas e hipersexuales parecen "gozar" de una larga tradición. Como indica Oscar Montero, al referirse a un libro de Max Nordau sobre la degeneración publicado en 1892, la "egomanía" y la "erotomanía" se asocian con la homosexualidad desde el "comienzo" de su "medicalización" (102).

34 "No es permisible que por medio de la 'calidad artística' reconocidos homosexuales ganen influencia que incida en la formación de nuestra juventud", citado en Montaner (180). Para una versión en inglés consúltese Granma Weekly Review (May 9, 1971).

${ }^{35}$ Citado en Montaner (179).

${ }^{36}$ Citado en Montaner (179).
} 
momentáneamente, de la labor de la sociedad. El tiempo y la energía requeridos para escribir y leer la opaca escritura de cubanos y homosexuales tales como José Lezama Lima, Severo Sarduy, Virgilio Piñera y Arenas chocan con los ideales del realismo social y tienden a reforzar los lazos entre la homosexualidad y el arte no utilitario. El sujeto narcisista e hipersexual goza, al parecer, de su propio arte.

En cierto sentido, Juan Goytisolo podría estar de acuerdo con esta conclusión. Paisajes después de la batalla, como casi todas las obras de Goytisolo a partir de Señas de identidad, ataca la estética del realismo social que el propio Goytisolo apoyaba en sus primeras obras. ${ }^{37}$ También ataca la política comunista o socialista que se asociara con dicha estética. La desilusión de Goytisolo para con el comunismo y sus promesas de un mundo mejor, se debe no sólo a la restriccón y censura del arte, el pensamiento y la creatividad, sino también a la persecución de homosexuales y otros "sujetos impropios". En En los reinos de taifa (1986), Goytisolo se dirige a sí mismo, o a alguna figuración de sí mismo, y describe "lo que estaba ocurriendo a tus hermanos de vicio nefando, de vilipendiado crimine pessimo y, junto a ellos, a santeros, poetas, ... lumpens, ociosos y buscavidas, inadaptados e inadaptables a una lectura unicolor de la realidad, a la luz disciplinada, implacable, glacial de la ideología" (175). Al igual que Arenas, Goytisolo describe la ideología comunista como aunada a un realismo monocromático, totalmente inadecuado a la "realidad [supuestamente] multicolor" de los homosexuales. Pero de manera mucho más decisiva que Arenas, Goytisolo aboga, especialmente en su autobiografía, por la solidaridad fraternal y defiende la comunidad de los oprimidos y marginados: una comunidad que es, en cierto sentido, una nación diferente, a la vez internacional y transnacional. ${ }^{38}$

O tal vez no: la nacionalidad, incluso cuando se califica de inter-y trans-, es un objeto de escarnio en Paisajes. Una imagen paladina de esto es la "desmonumentalización", o tal vez mejor dicho la "desacralización", de la tumba del Soldado Desconocido, aunque casi se podría decir que toda la obra-que comienza con una "invasión" de signos foráneos (caracteres árabes) y termina con una "hecatombe gráfica" - es una arremetida contra divisiones y fronteras nacionales. ${ }^{39}$ En la medida en que proyectos liberacionales puedan echar mano de

\footnotetext{
${ }^{37}$ Goytisolo satiriza las pretensiones revolucionarias del realismo social, asociándolo con un mundo totalitario y devastado: "Altavoces disimulados en el panteón y las almenas o torres de la muralla difunden un manifiesto grandilocuente en favor del uso de la literatura y el arte como arma o instrumento de combate, de un teatro y cine de denuncia y agitación, de una pintura y música movilizadoras y aguerridas, de una novela transmisora de consignas, de una poesía a la rosa convenientemente blindada: héroes positivos, ingenieros de almas, centrales eléctricas, minas y zanjas, ecuaciones moralopolíticas resueltas en términos de progreso industrial" (Goytisolo, Paisajes 194). Goytisolo alude aquí a varias obras asociadas con el realismo social: Central eléctrica de Jesús Pacheco, La mina de Armando López Salinas, y La zanja de Alfonso Grosso.

${ }^{38}$ El sentido de soledad parece mucho más agudo en las obras de Arenas que en las de Goytisolo, pero incluso en el momento que se podría suponer como el más solitario, el momento del suicidio, Arenas se dirige, por escrito, a otros: "Queridos amigos: debido al estado precario de mi salud y a la terrible depresión sentimental que siento al no poder seguir escribiendo y luchando por la libertad de Cuba, pongo fin a mi vida" (Arenas, Antes que anochezca 343).

${ }^{39} \mathrm{La}$ desmonumentalización se lleva a cabo mediante una sustitución racial/nacional (en la medida en que la nación es una "unidad" racial también): al ser exhumado el cadáver del soldado desconocido se descubre que éste no es ni breton, ni picardo, ni corso, ni provenzal, ni angevino (conjeturas ofrecidas en el texto), sino "un robusto negro" (Goytisolo, Paisajes 154).
} 
un vocabulario nacional, Goytisolo, no sin causa, se muestra escéptico. Pero el esceptismo, la sospecha, se extiende de modo que todo proyecto u organización de liberación se ve implicado. ${ }^{40}$ Ahora, si bien Goytisolo critica el proyecto comunista al "identificarse" con "homosexuales", más tarde critica los proyectos de los activistas gays: más exigentes, críticos, y propensos a acusar y reprochar que los que él llama sus "hermanos de vicio nefando". Ante lo que él identifica como estridencia y dogmatismo, Goytisolo llega a asociar a activistas gay con activistas comunistas y se distancia de ambos en aras de la libertad creadora. Es con esto en mente que, en Paisajes después de la batalla, Goytisolo fabrica "los Maricas Rojos". Los Maricas Rojos son terroristas que irrumpen en el domicilio del narrador, protagonista, o autor implícito para atarle una bomba al pecho y exigirle la redacción, monda y lironda, de su vida: o como reza el texto: "tu autocrítica, la historia completa de tus vicios e inclinaciones reales, tus fantasías y debilidades"(215). La exigencia de una "autocrítica" recuerda el "Caso Padilla", en el que el régimen de Castro exige que el escritor Heberto Padilla se acuse, en público, de actividades contra-revolucionarias. En otras ocasiones, Goytisolo presenta el "Caso Padilla" y la persecución de los homosexuales como los dos factores principales en su desencanto con la revolución cubana. ${ }^{41}$ Pero lo interesante en Paisajes es que Goytisolo toma la exigencia de una "autocrítica" y la extiende a las exigencias interpelativas de homosexuales radicales.

Goytisolo confecciona, así, una versión exuberante del activismo gay y lesbiano que, militantemente combativo, repite los excesos doctrinarios del comunismo. ${ }^{42}$ La presentación de los Maricas Rojos es deliberadamente estrambótica y no carente de humor. Sería tentador, por ende, dejarlo allí, si no fuera por otros datos - tanto "literarios" como "extraliterarios"- - que indican que algo bastante serio, por no decir trascendente, está en juego. En una entrevista con Javier Escudero, Goytisolo define su resistencia al movimiento gay y lesbiano en prácticamente los mismos términos que emplea para resistirse al realismo social, es decir, como una defensa de la creatividad artística, de la polisemia, la ambigüedad,

${ }^{40}$ A diferencia de lo que insinúan muchos de los críticos de Paisajes, no creo que el texto se escape de la ideología simplemente al burlarse de ella o al hacerla, muy figurativamente, estallar. Si es verdad que, como dice López-Baralt, "el relajo escamoteador [de Paisajes] ha terminado por neutralizar la seriedad de los ideales políticos y de la literatura misma" (4), esto sí que es serio: la neutralización de la seriedad de la política $-\mathrm{y}$, cómo no, de la literatura - sólo puede desembocar, irónicamente, en su reforzamiento. Las cosas, en política como en literatura, no son tan "relajadas".

${ }^{41}$ Para más sobre el caso Padilla, véase Casal. Goytisolo dedica todo un capítulo de En los reinos de taifa al caso. Según el escritor español, "[e]l caso Padilla no era un simple episodio infortunado de una lucha de tendencias internas sino fruto de una decisión política personal de Castro. Por unas razones que él solo conocía, el Líder Máximo había resuelto acabar con cualquier forma de disidencia y establecer la intangibilidad de su 'monolito ideológico"'(182). Goytisolo va incluso más alláal referirse, en el mismo libro, a "unas normas de saneamiento moral que recordaban asombrosamente a las dictadas por los regímenes fascistas" (186). Arenas también dedica un capítulo de su autobiografia, Antes que anochezca, al caso Padilla (162-167).

${ }^{42}$ Según Arenas, en Antes que anochezca, "[1] militancia homosexual ha dado otros derechos que son formidables para los homosexuales del mundo libre, pero también ha atrofiado el encanto maravilloso de encontrarse con una persona heterosexual o bisexual, es decir, con un hombre que sienta el deseo de poseer a otro hombre y que no tenga que ser poseído a la vez. Lo ideal en toda relación sexual es la búsqueda de lo opuesto y por eso el mundo homosexual actual es algo siniestro y desolado; porque casi nunca se encuentra lo deseado" (133). 
y la heterogeneidad. Tal y como lo concibe Goytisolo, el activismo gay está tendenciosamente anclado en la responsabilidad y la referencialidad: esto es así hasta el punto de reificar la identidad, esencializar la sexualidad, esclavizar y empobrecer la significación, y, lo que es peor, instrumentalizar el placer, incluyendo el placer del texto. En una extraña revisión de la historia, Goytisolo sugiere que los maricones no desean nada mejor que una historia contada rectamente.

Muchos de los planteamientos de Goytisolo, dentro y fuera de su ficción, se ajustan a los de Arenas. Los dos se oponen férreamente a las pretensiones internacionales y colectivas del comunismo, y los dos se oponen, aunque en distintos grados y con distintos fines, a la organización y activismo internacionales de homosexuales, de gays y lesbianas. Los dos insisten, además, en la individualidad, o aislamiento, de la enunciación y se dirigen, por lo común, a sujetos marcadamente individualistas. Con todo, el uso que Goytisolo hace del "tú" es especialmente enrevesado, implicando el autor y el lector, y apelando a una frágil comunidad de individuos aislados. Es importante tener en cuenta estos aspectos comunitarios, porque Goytisolo, dentro y fuera de sus obras literarias, parece mucho menos cercano a una especie de soledad "trágica" que Arenas: y esto a pesar de, o tal vez gracias a, designaciones tales como "misántropo", "anti-héroe", y "personaje atrabiliario" que se encuentran a lo largo de Paisajes. Goytisolo es, después de todo, uno de los escritores en lengua española más "comprometidos" con todo un conjunto de vivencias sociales y políticas que incluyen la situación de los inmigrantes en Europa, el racismo, el neo-colonialismo y la guerra en Bosnia. ${ }^{43}$ Pero junto con este sentido del compromiso, Goytisolo sigue defendiendo la (a veces radical) autonomía del texto. ${ }^{44}$ Su defensa de la creatividad es, por tanto, más intrincada que la de Arenas, aunque la soledad que se vislumbra en las obras de Arenas tampoco carece, evidentemente, de inquietudes comunitarias. ${ }^{45}$ En ambos escritores perdura un impulso que se podría calificar de individualista, más allá de "ellos", "los otros", y "los demás", más allá de colectivos y colectividades de comunistas y homosexuales.

Semejante defensa de la creatividad individual, como ya he indicado, dista mucho de ser sencilla. Ya sea que los comunistas persigan a los homosexuales o que sean sus más fieles aliados, la resistencia en los textos de Arenas y Goytisolo abriga una complicidad con el capitalismo. Ésta es una afirmación nada fácil, puesto que Goytisolo hace grandes esfuerzos por criticar el capitalismo, y puesto que otros hacen grandes esfuerzos por acusar a Arenas de ser primo, si no agente, de la CIA ${ }^{46}$ Como el tiempo apremia, sólo puedo hacer notar que

\footnotetext{
${ }^{43}$ Goytisolo examina el conflicto en Bosnia y sus repercusiones "internacionales" en su Cuaderno de Sarajevo.

${ }^{44}$ La oscilación entre el compromiso sociopolítico y autonomía literaria se ve sobre todo en un texto como Juan sin tierra. Más recientemente, y casi a la vez que escribe sobre la guerra en Bosnia, afirma, en El bosque de las letras, que "[e]l escritor aferrado al valor de la palabra, consciente de ser una rama, prolongación o injerto del árbol de la literatura, debe defender con uñas y dientes el derecho inalienable de la escritura a ser escritura" (11).

${ }^{45}$ Véase, por ejemplo, "Celestino y yo," en el que Arenas critica el realismo social, aboga por un discurso más personal (y más inconsciente), y se enfrenta con las tensiones entre el individuo y la colectividad.

${ }^{46}$ Rich y Argüelles le "acusan" a Arenas de ser parte del intento norteamericano de derrocar el régimen castrista.
} 
las imágenes de homosexuales capitalistas, viejos y corruptos, que chupan la sangre a la juventud de Cuba no carecen de réplica en los Estados Unidos. Quiero insistir en esto, porque si, a través de Arenas y Goytisolo, he vuelto a presentar el problema de la homosexualidad como un problema de la revolución cubana, la homofobia y el heterosexismo son igualmente marcas históricas del capitalismo. Lee Edelman, en un estudio excelente sobre las conexiones entre homosexualidad y comunismo en el disurso nacionalista de los Estados Unidos, examina el modo en que aquélla se percibía, junto con el comunismo, como una amenaza nacional. Echando mano de expedientes penales y reportajes periodísticos algo posteriores al McCarthyismo, Edelman examina el predominio de nociones de "conducta impropia (o perversión)" y muestra cómo el discurso nacionalista norteamericano agrupaba a comunistas y homosexuales, rojos y maricas: como si los Maricas Rojos salieran de la pluma de Joe McCarthy tanto como de la de Juan Goytisolo. Lo que es notable es el hecho de que la ansiedad nacional norteamericana se expresara en casi los mismos términos sexuales que la ansiedad nacional cubana. Edelman se refiere a la "idea, muy extendida, de la sexualidad gay como una plaga extranjera, una práctica anti-natural por anti-americana, que resultaba del embrollo con países y personas extranjeros durante la guerra" (269). Así era, pero también era así, como hemos visto, en Cuba: allí también la homosexualidad, tal y como se entendía en el dicurso oficial, era una plaga extranjera, una enfermedad venida de fuera, una cuestión de seguridad nacional. ${ }^{47}$ Las conexiones que Edelman señala entre homosexualidad y subversión "doméstica" parecen aplicarse a muchas naciones: para los Estados Unidos como para Cuba, el homosexual es el otro de la política nacional.

Ahora bien, aunque la homosexualidad se figura como el otro de muchas nacionalidades, hispanohablantes y angloparlantes, comunistas y capitalistas y, por supuesto, fascistas, la homosexualidad también puede constituir un problema, al menos para estos escritores, cuando invoca algo como su propia nacionalidad, o internacionalidad, cuando interpela a un sujeto y lo sujeta a una identidad que, de alguna forma, se resiste o rechaza. Pienso en el concepto de la Nación Marica, o Queer Nation, promulgado principalmente en los Estados Unidos y partes de Europa, pero vislumbrado, de otro modo, en otras partes del mundo: vislumbrado en Utopía Gay de José Rafael Calva y en la "gran hermandad gaya" (208) de Adonis García en El vampiro de la Colonia Roma de Luis Zapata así como en la "nueva mestiza lesbiana", sin raza, sin cultura, y sin país, de Gloria Anzaldúa (80) y en la "nueva minoría de amantes radicales" de José Joaquín Blanco (190); vislumbrado, incluso, en los "hermanos de vicio nefando" de Goytisolo y tal vezen la noción, articulada por Arenas en su autobiografía, de la homosexualidad como dispersa, no monógama, e instintivamente promiscua (90). Las obras de Goytisolo y Arenas son demasiado complejas y polémicas para ser sintetizadas en una conclusión facilona, sea sobre la homosexualidad, la nacionalidad, o la literatura. Lo único que puedo decir, corriendo a una conclusión tan imposible como insatisfactoria, es que sus lugares de enunciación y sus actos de interpelación son resbaladizos y auto-incriminatorios; que los dos, como escritores y hablantes, a veces parecen resistir lo que otras veces más buscan; que bregan con cuestiones de individualidad,

\footnotetext{
${ }^{47}$ En una frase tristemente célebre, Castro se refiere a la homosexualidad como un problema de disciplina y fidelidad: "una desviación de esta naturaleza choca con el concepto que tenemos de lo que debe ser un militante comunista" (Lockwood 124, traducción mía).
} 
autonomía, comunicación, y solidaridad; y que ponen la sexualidad, la homosexualidad, en un marco internacional, sin erradicar las huellas de la diferencia nacional. También sugieren - o tal vez provocan - una resistencia a su resistencia, una refiguración y recuperación de la colectividad, y en particular una reivindicación del poder de los Maricas Rojos. ${ }^{48} \mathrm{~A} \mathrm{mi}$ parecer, uno de los retos más acuciantes de la crítica, teoría, práctica y activismo actuales, dentro y fuera del hispanismo, es volver a examinar las relaciones y tensiones entre marxismo y homosexualismo, atendiendo a cuestiones de nacionalidad y sexualidad, pero también, a cuestiones de etnicidad y de economía, tanto local como global. Puede haber una moraleja aquí, a la vez un acertijo, un problema, una llamada y un revuelo de plumas, para "nosotros" todos.

\section{BIBLIOGRAFÍA}

Althusser, Louis. "Idéologie et appareils idéologiques díttat (Notes pour une recherche)". Positions. Paris: Éditions Sociales, 1976. 79-137.

Anderson, Benedict. Imagined Communities: Reflections on the Origin and Spread of Nationalism. London: Verso, 1991 ed.

Anzaldúa, Gloria. Borderlands/La Frontera: The New Mestiza. San Francisco: Aunt Lute Books, 1987.

Arenas, Reinaldo. Antes que anochezca. Barcelona: Editorial Tusquets, 1992. Arturo, la estrella más brillante. Barcelona: Montesinos, 1984. "Celestino y yo". Unión 6 (1967): 117-120.

Bejel, Emilio. "Senel Paz: Homosexualidad, nacionalismo y utopía”. Plural 269 (1994): 58-65.

Bergmann, Emilie L. \& Paul Julian Smith, eds. ¿Entiendes?: Queer Readings, Hispanic Writings. Durham: Duke University Press, 1995.

Blanco, José Joaquín. Función de medianoche: Ensayos de literatura cotidiana. México: Era, 1992 ed.

Butler, Judith. Bodies that Matter: On the Discursive Limits of "Sex". New York: Routledge, 1993.

Cabrera Infante, Guillermo. Mea Cuba. Barcelona: Paza \& Janés, 1992. "Paisajes con Goytisolo al frente". Quimera 27 (1983): 56-59.

Calva, José Rafael. Utopia gay. México: Editorial Oasis, 1984.

Casal, Lourdes. El caso Padilla: Literatura y revolución en Cuba: Documentos. Miami: Ediciones Universal, 1972.

\footnotetext{
${ }^{48}$ Un pasaje de la novela de José Rafael Calva es aquí sugerente: "La razón entonces de que mi utopía sea gay es para enfatizar que toda utopía tiene su encanto que podemos hacer de nuestra vida y espacio vital una utopía definida algo así como un sueño hecho realidad, lo que está a tono con Marx en cuanto a transformar la realidad y no sólo conocerla. Precisamente eso en mi texto hizo que mi propia utopía se volviera un reto para mí extraliterariamente y fuera de la novela, porque la homosexualidad hoy está muy injustamente reprimida al punto que por ejemplo en México oficialmente no existe, como tanto digo en el texto, y debemos todos esforzarnos por llevar su existencia a plena luz para así poder demostrar que es algo constructivo y perfectible" (159).
} 
Cruz-Malavé, Arnaldo. "Toward an Art of Transvestism: Colonialism and Homosexuality in Puerto Rican Literature”. ¿Entiendes?: Queer Readings, Hispanic Writings. Eds. Emilie Bergmann \& Paul Julian Smith. Durham: Duke University Press, 1995. $137-$ 167.

Edelman, Lee. "Tearooms and Sympathy, or, The Epistemology of the Water Closet". Nationalisms and Sexualities. Eds. Andrew Parker, Mary Russo, Doris Sommer, and Patricia Yaeger. New York: Routledge, 1992. 263-284.

Epps, Bradley S. Significant Violence: Oppression and Resistance in the Narrative of Juan Goytisolo. Oxford: Oxford University Press, 1996.

Escudero, Javier. "Muerte, erotismo y espiritualidad: Entrevista con Juan Goytisolo". Revista de Estudios Hispánicos 27 (1993): 123-139.

Foucault, Michel. La volonté de savoir. Histoire de la sexualité. Vol. I. Paris: Gallimard, 1976. 3 vols.

Freud, Sigmund. "The Economic Problem in Masochism". Trad. Joan Riviere. General Psychological Theory. New York: Macmillan, 1963. "Femininity". New Introductory Lectures on Psychoanalysis. Trad. James Strchey. New York: W. W. Norton, 1965. 99-119. Group Psychology and the Analysis of the Ego. Trad. James Strachey. New York: W. W. Norton, 1959.

Fuentes, Carlos. La nueva novela latinoamericana. México: Joaquín Mortiz, 1969.

Fuss, Diana. Essentially Speaking: Feminism, Nature \& Difference. Routledge: New York, 1989.

Geras, Norman. “Althusser's Marxism”. Western Marxism: A Critical Reader. London: Verso, 1978. 232-272.

Goytisolo, Juan. El bosque de las letras. Madrid: Alfaguara, 1995. Cuaderno de Sarajevo: Anotaciones de un viaje a la barbarie. Madrid: Ediciones El País, 1993. En los reinos de taifa. Barcelona: Seix Barral, 1986. Juan sin tierra. Barcelona: Seix Barral, 1975. Paisajes después de la batalla. Madrid: Espasa-Calpe, 1990. Las virtudes del pájaro solitario. Barcelona: Seix Barral, 1988.

Greenberg, David F. The Construction of Homosexuality. Chicago: University of Chicago Press, 1988.

Guasch, Oscar. La sociedad rosa. Barcelona: Anagrama, 1991.

Heath, Stephen. "Difference". Screen 19.3 (1978): 50-112.

Jay, Martin. Marxism and Totality: The Adventures of a Concept from Lukács to Habermas. Berkeley: University of California Press, 1984.

Jardine, Alice. "Men in Feminism". Odor di Uomo Or Compagnons de route?" Men in Feminism. Eds. Alice Jardine \& Paul Smith. New York: Methuen, 1987. 54-61.

Lancaster, Roger N. Life is Hard: Machismo, Danger, and the Intimacy of Power in Nicaragua. Berkeley: University of California Press, 1992.

Lapsley, Robert \& Michael Westlake. Film Theory: An Introduction. Manchester: Manchester University Press, 1988.

Leiner, Marvin. Sexual Politics in Cuba: Machismo, Homosexuality, and AIDS. Boulder, Colorado: Westview Press, 1994. 
Lockwood, Lee. Castro's Cuba, Cuba's Fidel. New York: MacMillan, 1967.

López-Baralt, Luce. "Juan Goytisolo aprende a reír: Los contextos caribeños de Makbara y Paisajes después de la batalla". Insula 40.468 (1985): 3-4.

Lumsden, Ian. Homosexuality, Society and the State in Mexico. Toronto: Canadian Gay Archives \& México: Solediciones, 1991.

Mirabet i Mullol, Antoni. Homosexualidad hoy. Barcelona: Herder, 1985.

Montaner, Carlos Alberto. Informe secreto sobre la revolución cubana. Madrid: Sedmay, 1976.

Montero, Oscar. "Julián del Casal and the Queers of Havana". ¿Entiendes?: Queer Readings, Hispanic Writings. Eds. Emilie Bergmann \& Paul Julian Smith. Durham: Duke University Press, 1995. 92-112.

Murray, Stephen O.\& Manuel Arboleda G. "Stigma Transformation and Relexification: Gay in Latin America". Latin American Male Homosexualities. Albuquerque: University of New Mexico Press, 1995. 138-144.

Murray, Stephen O. \& Wayne R. Dynes. "Hispanic Homosexuals: A Spanish Lexicon". Latin American Male Homosexualities. Albuquerque: University of New Mexico Press, 1995. 180-192.

Paz, Octavio. El laberinto de la soledad. México: Fondo de Cultura Económica, 1959. Paz, Senel. El lobo, el bosque y el hombre nuevo. México: Era, 1991.

Puig, Manuel. El beso de la mujer araña. Barcelona: Seix Barral, 1976 y 1981.

Ramos Otero, Manuel. Invitación al polvo. Río Piedras: Plaza Mayor, 1991.

Rich, Ruby \& Lourdes Argüelles. "Homosexuality, Homophobia, and Revolution: Notes Towards an Understanding of the Cuban Lesbian and Gay Male Experience, Part I". Hidden From History: Reclaiming the Gay and Lesbian Past. Ed. Martin Duberman, Martha Vicinus \& George Chauncey, Jr. New York: Meridian (Penguin), 1989.

"Homosexuality, Homophobia, and Revolution: Notes Toward an Understanding of the Cuban Lesbian and Gay Experience, Part II". Signs 11 (1985): 120-136.

Salessi, Jorge. "The Argentine Dissemination of Homosexuality, 1890-1914". Journal of the History of Sexuality 4.3 (1994): 337-368.

Sarduy, Severo. De donde son los cantantes. Ed. Roberto González Echevarría. Madrid: Cátedra, 1993 ed.

Scott, Joan W. "Experience"”. Feminists Theorize the Political. Eds. Judith Butler \& Joan W. Scott. New York: Routledge, 1992. 22-40.

Sedgwick, Eve Kosofsky. Between Men: English Literature and Male Homosocial Desire. New York: Columbia University Press, 1985.

Showalter, Elaine. Sexual Anarchy: Gender and Culture at the Fin de Siècle. New York: Penguin, 1990.

Sommer, Doris. Foundational Fictions: The National Romances of Latin America. Berkeley: University of California Press, 1991.

Varo, Carlos. Rosa mystica. Barcelona: Seix Barral, 1987.

Young, Allen. Los Gays bajo la revolución cubana. Trad. Máximo Etlis. Madrid: Playor, 1984.

Zapata, Luis. Las aventuras, desventuras y sueños de Adonis García, el vampiro de la Colonia Roma. México: Grijalbo, 1979. 